
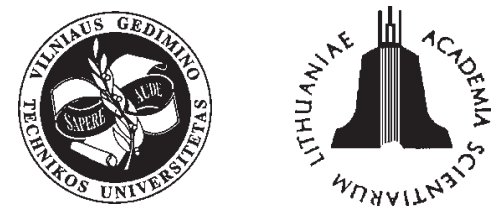

ISSN 1392-3730 print / ISSN 1822-3605 online

JOURNAL OF CIVIL ENGINEERING AND MANAGEMENT

http:/www.jcem.vgtu.lt

2006, Vol XII, No 1, 21-28

\title{
ANALYSIS OF DISTRICT HEATING NETWORK MONITORING BY NEURAL NETWORKS CLASSIFICATION
}

\author{
Pawel Malinowski ${ }^{1}$, Piotr Ziembicki ${ }^{2}$ \\ ${ }^{1}$ Technical University of Wroclaw, Institute of Air-Conditioning and District Heating, 4/6 Norwida Str, \\ 50-370 Wroclaw, Poland. E-mail: Pawel.Malinowski@pwr.wroc.pl \\ ${ }^{2}$ University of Zielona Gora, Institute of Environmental Engineering, 15 Prof Z. Szafrana Str, \\ 65-246 Zielona Gora, Poland
}

Received 29 April 2005; accepted 21 Dec 2005

\begin{abstract}
The paper proposes an alternative approach to the problem of district heating monitoring parameters selection, based on conditions, taken, for instance, from a specific real district heating network supplemented with tests data and expert knowledge.
\end{abstract}

Keywords: district heating networks, monitoring, neural networks, neural classification.

\section{Introduction}

According to the provisions of Kyoto Protocol, it is necessary to take actions against climate change and international cooperation for sustainable development on a global level. This requires reorientation of the State's energy policy. One of the methods to fulfil the abovementioned obligations is to develop new and renewable forms of energy. However, this involves considerable investments, which would be very difficult to achieve in the Polish circumstances. Therefore, it is necessary to improve the energy efficiency of existing systems through optimisation of combined heat and power generation, rationalisation of heating networks used for distribution of heating media, as well as heating substations.

The analysis of a complex heating system operating in diverse and often unpredictable conditions involves creation of complex mathematical models. In many cases, however, the present level of knowledge does not make it possible to map all essential features of the system. Accurate computational methods are not available, either. In these circumstances, new methods are continuously looked for to allow conducting a fast and errorfree analysis based on both historical data and measurement data acquired on a current basis via system monitoring. The artificial neural networks are perfectly suited for this purpose. They have many features distinguishing them from other data processing systems. The most important of these features are: ability to work effectively even when they are partly damaged, ability to make generalization, interpolation and prediction, as well as little susceptibility to errors in data sets.
Due to their features, the artificial neural networks make it possible to create mathematical models of systems with complicated structure, which operate in a manner that cannot be fully anticipated. As a result, this tool is extensively used to conduct research in many fields of science.

Żurada [1] presents, inter alia, a model of neural network classifying encephalographic signals (EEG) used in medicine, and an ALVINN network steering a vehicle on the road. Tadeusiewicz [2] describes the application of neural networks for steering a robot arm, sonar signal recognition (in military submarines), as well as for controlling the valves which feed fuel to rocket engines, and those supporting the operation of power plant BC Hydro in Vancouver. Korbicz [3, 4] presents neural networks used for solving optimisation and modelling problems and identifying dynamic objects (used in automation and control) and describes a diagnostic neural system for the combined heat and power plant simulator.

Malinowski [5] presents the opportunities to use artificial neural networks for an analysis of building heat accumulation phenomenon.

There is a number of applications described in the bibliography [6-15], inter alia, for classification of experimental data, control of heating systems, forecast of heating system load, image and sound recognition and their classification.

In the context of the bibliographic analysis that has been carried out and due to huge amounts of data to be dealt with, the selection of neural simulation and classification as a tool for modelling and analysis of the heating system is justified. 
This article is a report of the research conducted by the authors, and it is aimed to demonstrate that the utilisation of artificial neural networks make it possible to carry out the analysis of locations for monitoring the district heating network, leading to the reduction of their number and, at the same time, to obtaining such topographic distribution of telemetry chambers that will allow gaining the full picture of heating system status. The research was based on an active heating system of one of the largest cities in Poland.

\section{Monitoring and telemetry systems}

The proper operation of district heating network requires full information on its functioning and ability to react promptly to changes that occur in it. Therefore, it is necessary to apply an automatic control system coupled with monitoring and telemetry systems that will allow the control of parameters and remote change of equipment settings.

Such systems should have features that will, among the other things, allow for:

- cyclic readout of parameters and their processing into physical units,

- control of crossing technological limits and permissible rates of parameter change,

- visualisation of current values of technological parameters and trends,

- generation of alarm and status messages and technological reports,

- remote control,

- system equipment diagnosis and testing.

The analysis of changes in heating medium parameters allows the billing of heat consumers, which would be not possible without a number of measuring instruments, indications of which provide information on the current values of parameters being measured. The information gathered during a longer period is used for data analysis and further improvement of a particular part of network.
The monitoring of heating network parameters may be accomplished with the use of equipment installed in heating substations or network chambers. If measuring points are scattered, the efficient communication between them is critical. The distance between the transmitter and the receiver may vary considerably and may reach even tens of kilometres. The most often used methods for communication between automatic control equipment located at the measuring points include leased or subscriber's line communication, GSM or GPRS technology, and radio-modem communication.

One of the most important elements of the monitoring and telemetry system is the SCADA software intended for data acquisition, management and automation as well as for its visualisation. The present-day SCADA systems feature clear and intuitive presentation of monitored parameters, ensure the data processing according to the client-server model, modularity, openness, reliability and expandability; at the same time they should allow conducting security policy and defining users' rights.

An example of the SCADA software is Wonderware's InTouch system, designed for visualisation and control of industrial processes. The InTouch software is available as a simple single-station application, distributed systems based on Client/Server architecture or systems utilising the potential of Industrial Application Server or Terminal Services. The InTouch applications feature graphical presentation of the production process. Implemented in the software, there are a number of tools for object generation (simple graphical elements, bitmaps). The script editor, QuickScript makes it possible to extend the application functionality and to better tailor it to user's needs, which makes the InTouch package one of the most flexible SCADA systems.

Fig 1 shows a synaptic view prepared in the InTouch application to visualise the management of production processes in the boiler house operated within the heating system of the city of Koło in central Poland. The synaptic view contains graphical elements representing equipment and measuring instruments installed in the boiler

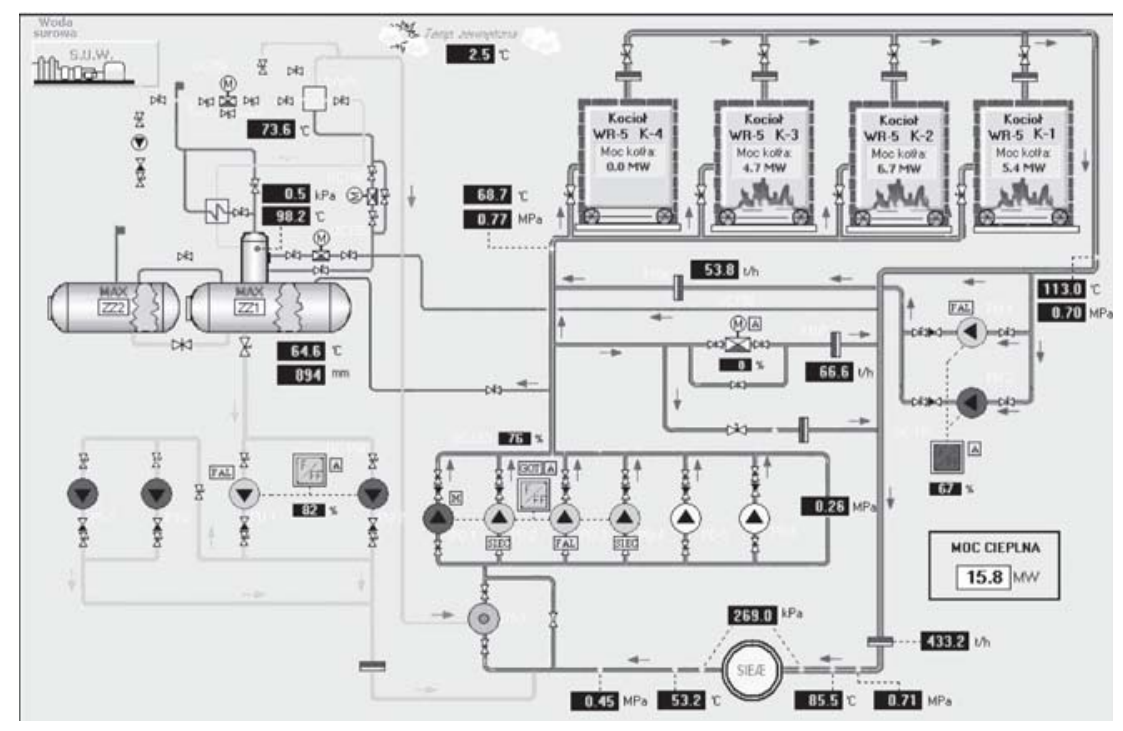

Fig 1. Example view of monitored object (heat-generating plant) 
house being monitored. The graphical elements representing measuring instruments and control equipment allow tracing the state of boiler-house operating parameters, as well as their modification.

The structure of monitoring and telemetry system is dependent on types and parameters of the equipment to be monitored, range and tasks to be performed. When creating such a system, it is necessary to make decisions concerning the design and characteristics of sensors and measuring transducers, technical means of visualisation, methods of data transmission, as well as types and functions of tool and application software. At the stage of concept, it is necessary to define the method of communication between instruments, including connector types, connection standard, communication protocol etc. Communication capabilities and logical structure are the basis for defining network topology, or configuration of connections between the telemetry system devices. When designing the network topology, it is necessary to take into account the adequate flow capacity, redundancy (eg two separate data transmission lines), and fast communication channels to support messages in an emergency situation.

When designing the monitoring and telemetry system it is essential to assign heating subsystems and chambers in which the telemetry equipment will be placed in order to obtain the full information about network conditions. The telemetry system features associated with the technical characteristics of automatic measurement and control system, as well as limitations resulting from data communication infrastructure, and organisational and legal conditions affect the decisions on location of the equipment. The modern methods of data processing, eg those that utilise neural networks, allow for the analysis of incomplete data which results in making decisions with regard to the tested arrangement or system. Consequently, it is not necessary to have measurement data from each heating substation or chamber, which is of great significance in the context of investment and maintenance costs.

It must be stressed that the bibliography does not provide any rule, method nor algorithm that would allow selecting the minimum number of elements and rational location of points in the heating network to ensure that their monitoring would provide the full image of heating network conditions.

The complexity of monitoring and telemetry systems, and considerable number of parameters that must be taken into account during their design, as well as the imperfection of traditional modelling methods for heating systems call for searching new methods supporting the decisions on selection of district heating network monitoring points. An example of such methods are artificial neural networks, which the authors of this publication have utilised for rationalisation of the existing heating network. In further part of the study, the basic information on artificial neural networks, methods of their teaching and neural classification are briefly presented.

\section{Artificial neural networks}

Artificial neural networks is a modelling technique capable of mapping complex non-linear functions. Like in their biological archetype, the processing of information in such structures is accomplished through the network of computing nodes (neurons) and their interconnections. The basic features which distinguish them from other data processing systems include ability to work effectively even when they are partly damaged, parallel and distributed processing (in hardware realisation), ability to make generalisation, interpolation and prediction, as well as little susceptibility to errors in data sets. The most important feature of neural networks is their ability to adapt (or ability to learn) making possible such selection of parameters that will allow the adaptation of network operation for solving a specific problem. When designing a neural network, no operational algorithm is defined for its particular elements but only its architecture, original values of weights and training method.

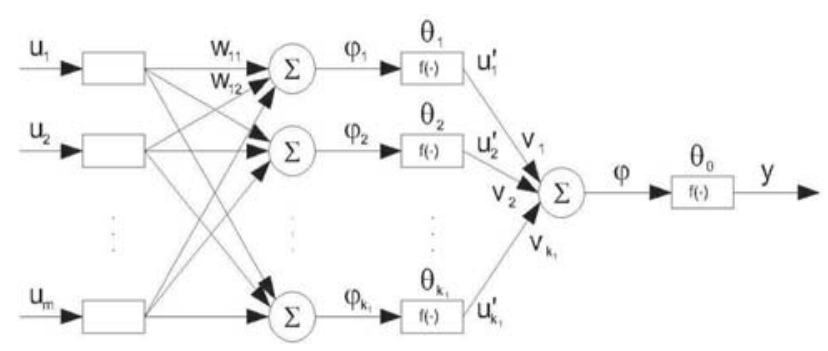

Fig 2. Diagram of two-layer perceptron according to Korbicz [4]

Most of the recently created and used networks have the layer structure in which an input layer, an output layer and hidden layers are distinguished in respect of the travelling direction of processed signals. In general, they can be divided into feed-forward, recurrent and cell networks.

Fig 2 shows the structure of two-layer neural network according to Korbicz [4], which can be described by the following equations:

$$
\begin{aligned}
& y=f\left(\sum_{k=1}^{k_{1}} v_{k} u_{k}^{\prime}-\theta_{0}\right), \\
& y=f\left(\sum_{i=1}^{m} w_{k i} u_{i}-\theta_{k}\right),
\end{aligned}
$$

where $\theta_{0}, \theta_{1}, \ldots, \theta_{k_{1}}$ are activation block thresholds of network elements ( 0 corresponds to output element, and $1, \ldots, k_{1}$ to hidden layer elements), $w, v$ designate weight factors, $u$ neuron input signals, and $k=1,2, \ldots, k_{1}$, $i=1,2, \ldots, m$.

Both hidden layer neurons and the input element divide the inputs space into two half spaces, with one of them to be a multilateral convex set. Values of weights entering the input neuron and its threshold will deter- 
mine which hyperplanes defined in the hidden layer will restrict the convex set that is formed, and what output activity will be for the states within this set. However, the expansion of a simple perceptron into a two-layer structure does not guarantee that any space representation will be possible to accomplish. This is only possible with the use of three-layer perceptron.

When taking the type of activation function as a division criterion, RBF networks (Radial Basis Functions) and Probabilistic Neural Networks (PNN) are distinguished, and Generalized Regression Neural Networks (GRNN) are distinguished in respect of the purpose criterion. PNN networks are designed to solve classification problems, and GRNN networks are used for solving regression problems.

The behaviour of a neuron network is determined to a great extent by its structure and weight vectors on the connections between particular neurons. It is not possible to determine those vectors a priori, so in use there are iterative multi-stage methods of neuron network „programming”, which is called neural network teaching. In order to allow the application of these methods, it is necessary to supplement the artificial neuron network model with a weight changing processor and error detector. The learning process may be conducted with or without a teacher. The learning with a teacher is done by entering an input image in the network inputs and determining the output. If the output is correct, there is no basis for making any changes in the system, otherwise the values of weights should be modified in such a manner that the error is completely reduced. The error is determined as the difference between the value of input signal and the value of signal determined by the system. The method of back propagation of error is most often used for that purpose. The graphical presentation of the algorithm is shown in Fig 3.

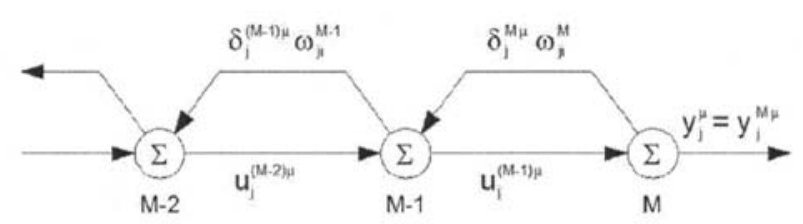

Fig 3. Diagram of error back propagation algorithm according to Korbicz [4]

The error back propagation algorithm requires that the operations defined by Korbicz in his paper [4] be performed for each learning pattern applied to the network input:

- apply learning vector $u^{\mu}$ to the network input,

- determine output values $u_{j}^{m \mu}$ of each element for particular layers of neural processing, from the first hidden layer to the output layer,

- calculate error values $\delta_{j}^{M \mu}$ for the output layer according to the formula

$$
\delta_{j}^{M \mu}=f^{\prime}\left(\varphi_{j}^{M \mu}\right)\left(y_{j}^{z \mu}-y_{j}^{\mu}\right),
$$

- calculate squared error sum value $\zeta_{\mu}$ according to the formula

$$
\xi_{\mu}=\frac{1}{2} \sum_{j=1}^{n}\left(\delta_{j}^{\mu}\right)^{2}
$$

where

$$
\delta_{j}^{\mu}=y_{j}^{z \mu}-y_{j}^{\mu}=y_{j}^{z \mu}-\sum_{i=1}^{n_{0}} w_{j i} u_{i}^{\mu},
$$

- perform back propagation of output error $\delta_{j}^{M \mu}$ for particular elements of the hidden layers by determining $\delta_{j}^{m \mu}$ according to the formula

$$
\delta_{j}^{m \mu}=f^{\prime}\left(\varphi_{j}^{m \mu}\right)^{n_{m+1}} \sum_{l=1}^{(m+1) \mu} \delta_{l j}^{(m+1)},
$$

- update the weights, first between the hidden and output layers, and then successively between the hidden layers moving towards the input layer.

The error back propagation does not guarantee that the global minimum of error function will be found in the weight space in case it features rich topology. It arises from the fact that this algorithm is based on the maximum decline method which is not capable of determining the global minimum.

The essential problem, from the point of view of this publication, is the classification issue defined as the transformation of point from the input space to the output space, which is called the classification space. The purpose of the classification network is to estimate the probability that a case belongs to a given class; in fact, during the training process such a network learns to estimate the function of probability density represented by the data gathered. Modern methods of probability density function estimation are based on nucleus approximation that operates using the following principles:

- presence of a certain case in a certain point of the input space means high probability density in this point,

- concentration of cases that are close to each other indicates an area of high probability density,

- areas away from any known cases feature probability density approaching zero.

In the nucleus estimation, simple (nucleus) functions are located where any available case occurs, and then they are added together in order to obtain the estimator of total probability density function. In typical cases, each nucleus function is a Gauss function, and such an approach to the probability density function approximation, which is very similar to the application of neural networks of radial base functions, initiated the creation of probabilistic neural networks and neural networks performing generalised regression. For the performance of classification tasks, besides PNN networks, multi-layer perceptrons are most often used as well as networks with radial base functions and linear networks. 
In probabilistic neural networks, there are three layers: input, radial and output. The radial neurons have parameters that are directly copied from training data with each of them modelling the Gauss function centred on "its own" training case. In the output layer, each class is represented by one neuron. Each of these neurons has connections with radial neurons, which have been set above the points belonging to a given class. Thus, the output neurons add together the values which appear as outputs from the radial neurons belonging to the class corresponding to a given output neuron. The values of output neurons are thus proportional to the nucleus estimators of probability density functions for various classes and after the application of standardisation to ensure that their total is one, they constitute direct estimations of probability of belonging to particular class.

\section{Neural simulation of district heating networks}

The tested heating system includes a variety of heat consumers with different consumption characteristics and heat demand values. The heating systems consists of approx 3700 heat substations (varying in structure and parameters), fed by 72 boiler houses and heating stations, and heat distribution network approx $370 \mathrm{~km}$ in length. The overall area of heated objects is approx $10198725 \mathrm{~m}^{2}$, and cubic capacity approx $49201773 \mathrm{~m}^{3}$ [16].

Within the heating network, 16 telemetry chambers have been selected, in which measuring instruments for the monitoring system have been installed.

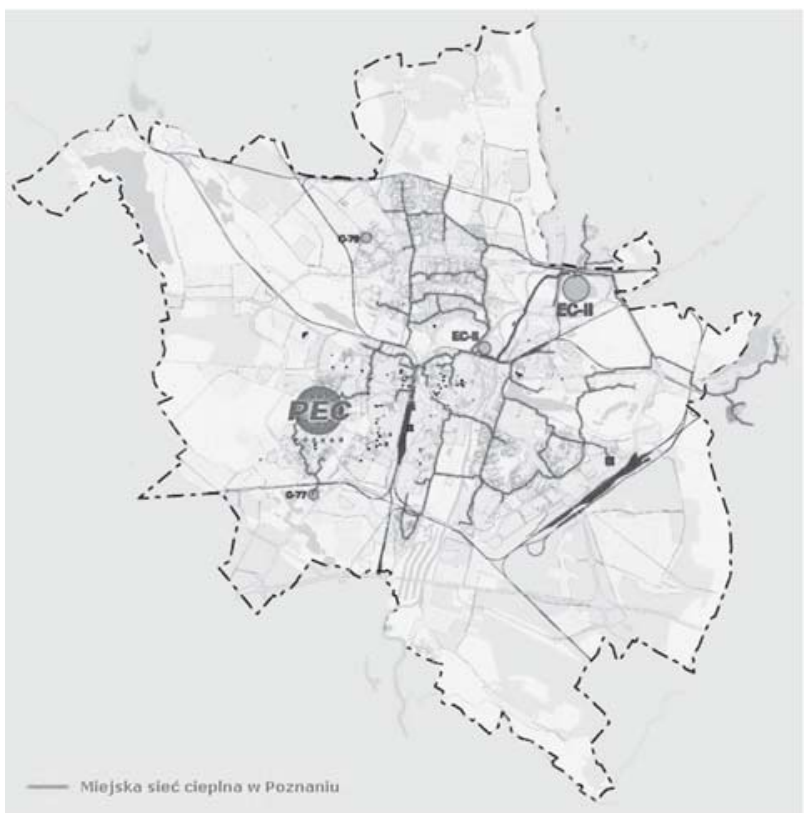

Fig 4. Heat distribution network diagram superimposed on city map

Fig 4 shows a diagram of the existing heat distribution network superimposed on the city map. It contains the pipeline connecting the sources, which did not exist in the period analysed in this study.
The Heat Distribution Company provided data regarding both the structure and topology of the system, and also balance data and measurement data from the telemetry chambers. Due to some changes implemented in the operating system of monitoring and telemetry, and the resulted data incoherence, shortages and errors, it was decided to analyse the data for the period from Jan 1996 to Dec 1999, with the most credible and complete data for the years 1996 and 1997. In 1998, the parameters were recorded in the period from January to April only.

The data obtained from the Heat Distribution Company, among others, included:

- digital map of the heat distribution system,

- database of the heat substations,

- meteorological data covering the years $1991 \div 1999$.

The execution of the research project required neural classification of heating system state to the specific, predefined category. Due to the specificity of problem for which the neural model was built, a number of tests were performed aimed at finding both optimal neural network and the best set of training data as well as the set of heating network state categories.

In the designed neural model, the issue of defining heating network state categories was particularly difficult due to the complexity of relationship between the network parameters. The relationship between flow, pressure, feeding temperature and cooling, as well as the impact of such elements as irregularities in domestic hot water consumption, seasonal technologies, night and weekend temperature reductions that are difficult to describe in mathematical terms, in principle make it impossible to define the precise rules of qualification to particular class. Meteorological data, such as data containing hourly distribution of external temperatures for each day of the tested period, allowed the solving of this problem through the determination of specific state sets (network state categories) on the basis of external temperature, type of day ( $\mathrm{R}$ - working day, $\mathrm{W}$ - holiday) and time of the day ( $\mathrm{N}$ - nighttime, $\mathrm{D}$ - daytime). After assuming such a criterion for heating network state image generation, it was possible to build the set of states being a compilation of the above conditions. Another motivating argument for such a selection of parameters was practical inability to analyse very large numbers of data available.

The construction and testing of neural models of the heating network was started with the determination of two research directions. The first one focused on the model in which single neural networks classified all categories of heating network states. In the utilised neural networks, the one-of- $\mathrm{N}$ coding was applied and such a model was called an integrated neural model. The task of the other research direction was the creation of selfcontained neural networks able to classify group categories of the heating network states. In the utilised neural networks, two-state (or maximum four-state) coding was applied and such a model was called a partial neural model. 
An important stage in the design of learning data set is the determination of number of cases which must be gathered so that the neural network learning process will bring acceptable results. The determination of learning set size creates big problems since there are no strict rules to help resolve this issue. The rules found in the bibliography very often state that the number of cases depend on the network size, requiring the number of learning patterns to be as many as 10 times of the number of connections in a neural network. In effect, the required number of cases is also dependent on the complexity of function to be modelled, however, this relationship usually has an unknown form, so it is difficult to define an algorithm that would help determine how many elements in the learning sequence are really needed.

Another important element making the network learning process difficult to achieve is the defectiveness of data forming the learning set, which means that the proper data are contained in the proper set but they do not bring as much information as they should. The reasons for that may be different, for example, distortion caused by noise occurring in the set, incomplete data etc.

The telemetry data obtained, and the computer simulation model built were used to define a series of training, validating and testing data sets. The designed neural models were based on both the training data sets built on the basis of computing results generated from the simulation model (neural models DSZ.1, DSZ.2, DSC.ZT01 - DSC.ZT19), and on the basis of measuring data obtained from the monitoring of the tested heating system (neural models DTZ.1 $\div$ DTZ.4, DTC.ZT01 $\div$ DTC.ZT19). In both types of neural models, the training, validating and testing data featuring various numbers of training standards and presence or lack of defective data. In both of them, a variety of neural network types were tested, such as MLP, RBF, linear networks and PNN, among others. In total, 812 neural networks were tested, allowing the formulation of conclusion that both perceptron and linear-type neural networks were completely not suitable for heating network state classification, and that the best classification quality in most neural model variants was shown by probabilistic neural networks (PNN).

The analysis of the results obtained from neural simulation of the heating network allowed the selection of neural networks which were then utilised for further research efforts. Validation error was the main acceptance criterion for network selection.

In the case the values of the above parameter were similar, better qualification quality or less complicated structure (smaller number of layers and neurons in a layer) were decisive during the selection of networks. Neural networks tested in the partial neural model (except for the rejected networks) showed similar values of the validation error and similar qualification quality. Due to the clear symptoms of network overlearning or insufficient number of learning patterns, 10 networks from the partial model based on simulation data and 2 net- works from the partial model trained by telemetry data were rejected.

The research that was carried out allowed the selection of neural networks that achieved average classification quality above 0,94 . This means that, in average, more than $94 \%$ of state images presented to the neural networks during the training process were classified correctly. One of the networks selected for further testing is shown in Fig 5. The diagram presents a probabilistic three-layer neural network, with the first layer consisting of 54 artificial neurons, the hidden layer consisting of 615 neurons, and the output layer comprising 4 neurons. The network input is fed by 54 signals, and a single signal is received at the network output. The validation and testing processes resulted in respectively $65 \%$ and more than $62 \%$ of correctly classified network categories. The built models achieved such parameters for complete input data, ie measured (or computer simulated) parameters in all telemetry chambers functioning in the tested heating network.

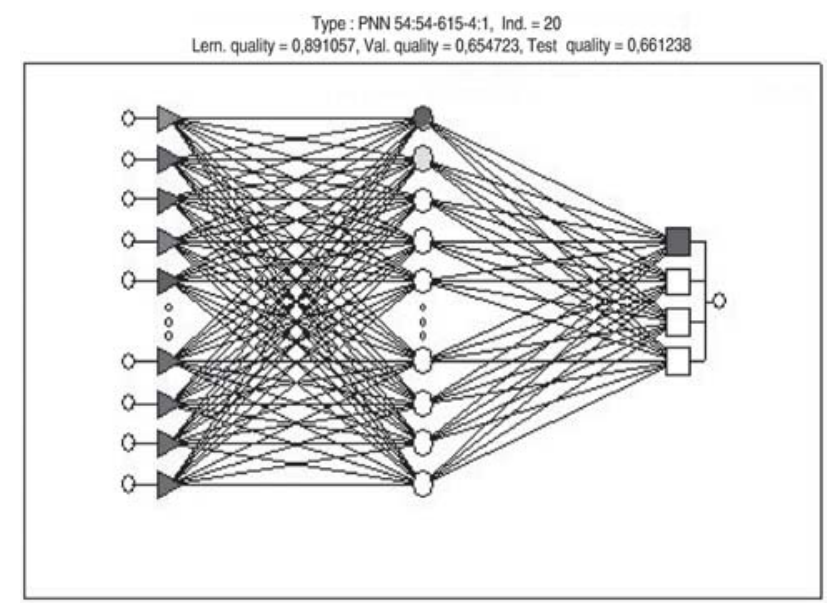

Fig 5. Probabilistic neuron network selected for further testing

The determination of minimum number and optimal topographic arrangement of telemetry chambers was carried out by eliminating particular input data of the neuron networks (which were, at the same time, the parameters measured or simulated in particular telemetry chambers of the heating network) and testing the classification quality. It was assumed that, in respect of the economic effect, only removing measurements of all parameters (flow, pressure and temperature) in a given telemetry chamber would make sense. It was because of the fact that only such a solution allowed the abandonment of transmission equipment, telecommunications line etc.

The criterion deciding on acceptance or rejection of the variant of number and topographic arrangement of telemetry chambers was the classification quality of state images of heating network by the neural network. It was assumed that an average decrease in classification quality by more than $15 \%$ meant that the telemetry chambers remaining in the heating system should continue to function. 
The neural models were trained and tested with the use of measurements of network medium parameters performed in all telemetry chambers. In order to analyse the possibility to remove the control and measurement instruments from the selected chambers, 8 variants of heating network arrangements were prepared. In each of these variants, the number and topographic arrangement of telemetry chambers were adjusted. The economic effect can be achieved in the case of complete elimination of telemetry and control in a given network location. Therefore, it was assumed that the elimination of measurements in a chamber would mean no readouts of flow rate, pressure and temperature.

Fig 6 shows one of the diagrams of the tested heating network with removed telemetry chambers presented in grey.

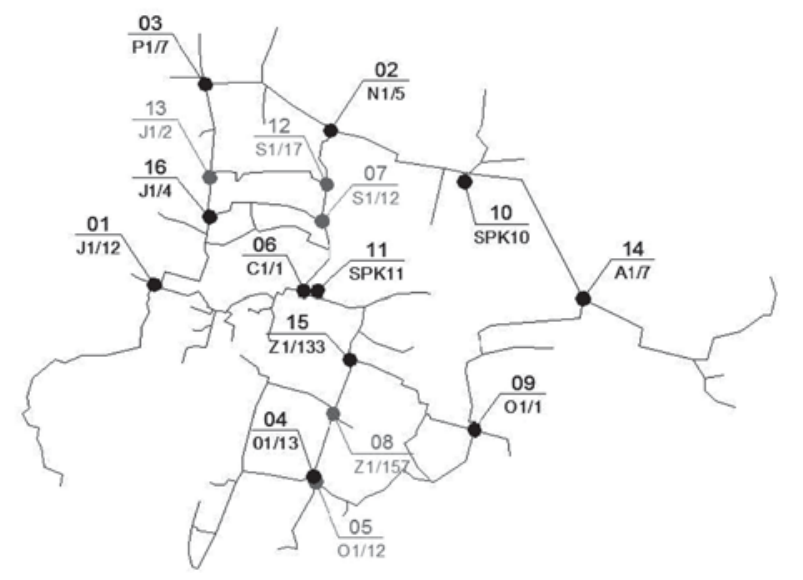

Fig 6. Variant IV: removed measurements in chambers $13,07,08,12$

The neuron simulation of the prepared variants of number and arrangement of telemetry chambers was performed separately for all neural networks.

The analysis of simulation results shows that, for each neural network, the classification quality of heating network state images decreases with the increase of number of removed telemetry chambers. The maximum average decrease in classification quality occurred in Variant VIII for neural network No 20 (PNN 63:63-6000$73: 1$ ) in DTZ.1 neural model, ie in the probabilistic threelayer neural network with 63 input neurons, 6000 neurons in the hidden layer and 73 neurons in the output layer. The maximum average decrease in classification quality (for all neural networks and variants functioning in a given class of neural model) was recorded for the integrated neural model based on telemetry data, and this amounted to $48 \%$. In the partial model based on the data obtained from computer simulation, this factor amounted to $9 \%$.

The analysis of simulation results allowed for the determination of variants of number and topographic arrangement of telemetry chambers in which the monitoring of parameters make it possible to map the state of tested heating network through the network or network group functioning in a given model.
In the integrated neural model based on both the telemetry data and measuring data, only Variant I is acceptable, in which the parameters measured in telemetry chamber No 13 were removed.

In the partial neural model built on the basis of the data obtained from computer simulation of the heating system, Variant IV is acceptable, in which the parameters measured in telemetry chambers Nos 13, 07, 08 and 12 were removed.

In the partial neural model built on the basis of the data obtained from tested heating system, Variant III is acceptable, in which the parameters measured in telemetry chambers Nos 13, 07 and 08 were removed.

\section{Summary}

The following conclusions may be drawn from the performed tests:

1. The heating network simulation model built on the basis of information about its topology and based on the balance and telemetry data achieved good conformity of the results obtained in respect of the telemetry data, which made it possible to use these results for construction of learning patterns for neural models.

2. The analysis of classification results in variants with various number and arrangement of measuring chambers showed that, for each neural network, the classification quality of heating network state images decreases with the increase of number of removed telemetry chambers.

3. In the integrated neural model based on both telemetry data and measuring data, it is acceptable to remove telemetry chamber No 13 only.

4. In the partial neural model built on the basis of the data obtained from computer simulation of the heating system, the acceptable variant is the one in which the parameters measured in telemetry chambers Nos 13, 07, 08 and 12 were removed.

5. The removal of 4 telemetry chambers (partial neural model based on simulation data) constitutes $25 \%$ of all telemetry chambers currently functioning in the tested heating system.

6. In the partial neural model built on the basis of the data obtained from tested heating system, the acceptable variant is the one in which the parameters measured in telemetry chambers Nos 13, 07 and 08 were removed.

7. The presented working method, meant as a set of activities and resources, helped achieve its purpose with the measurable effect of reducing by 4 the number of telemetry chambers in the tested heating network.

8. Further research is needed to improve the qualification quality of heating network state categories, both for complete neural network input data and for the variants with their limited number. The objective of further research should be the full generalisation of the method, allowing for the algorithm that will make it possible to determine the minimum number of telemetry chambers and their optimal arrangement for any heating system. 


\section{References}

1. Żurada, J.; Barski, M.; Jędruch, W. Artificial neural networks (Sztuczne sieci neuronowe). PWN, 1996. 373 p. (in Polish).

2. Tadeusiewicz, R. Basic introduction to neural networks techniques with examples (Elementarne wprowadzenie do techniki sieci neuronowych z przykładowymi programami). Akademicka Oficyna Wydawnicza PLJ, 1998. 312 p. (in Polish).

3. Korbicz, J.; Mokin, B. Mathematical methods in problems of systems and controls in energy sector (Metody matematyczne $\mathrm{w}$ zagadnieniach kontroli i sterowania $\mathrm{w}$ energetyce). Zielona Góra, WSI, 1990. 158 p. (in Polish).

4. Korbicz, J.; Obuchowicz, A.; Uciński, D. Artificial neural networks. Basic concepts and implementations (Sztuczne sieci neuronowe. Podstawy i zastosowania). PLJ, 1994. 251 p. (in Polish).

5. Malinowski, P. Implementation of fuzzy sets theory and neural networks in environmental engineering (Zastosowanie teorii zbiorów rozmytych i sieci neuronowych w inżynierii środowiska). PhD dissertation Wroclaw, Poland. PWr, 1996. 194 p. (in Polish).

6. Adamczak, R Implementation of neural networks to classification of experimental data (Zastosowanie sieci neuronowych do klasyfikacji danych doświadczalnych). $\mathrm{PhD}$ dissertation, Poland. UMK, 2001. 123 p. (in Polish).

7. Ben-Nakhi, A.; Mahmoud, M. A. Cooling load prediction for buildings using general regression neural networks. Energy Conversion \& Management, Vol 45, Issues 13-14, 2004, p. 2127-2141.

8. Bishop, Ch. Neural networks for pattern recognition. Clanedron Press, 1998. 504 p.

9. Doutzauer, E. Simple model for prediction of loads in dis- trict-heating systems. Applied Energy, Vol 73, Issues 3-4, 2002, p. 277-284.

10. Kalogirou, S. A. Application of artificial neural networks in energy systems. A review. Energy Conversion \& Management, Vol 40, Issue 10, 1999, p. 1073-1087.

11. Krzyżak, W.; Lichota, J. Implementation of neural networks in control of district heating networks (Zastosowanie sztucznych sieci neuronowych w sterowaniu systemami ciepłowniczymi). The 9th International Conference of air conditioning \& district heating, Wroclaw, Poland. 1998, p. 273-276 (in Polish).

12. Lichota, J. Perspectives of implementation of mathematical models and new modeling techniques in district heating (Perspektywy zastosowania modeli matematycznych i nowoczesnych technik obliczeniowych w ciepłownictwie). In: The 9th International Conference of Air Conditioning \& District Heating, Wroclaw, Poland. 1998, p. 297-302 (in Polish).

13. Olofsson, T.; Andersson, S.; Ostin, R. A method for predicting the annual building heating demand based on limited performance data. Energy and Buildings, Vol 28, Issue 1, 1998, p. 101-108.

14. Olofsson, T.; Andersson, S. Long-term energy demand prediction based on short-term measured data. Energy and Buildings, Vol 33, Issue 2, 2001, p. 85-91.

15. Olofsson, T.; Andersson, S. Overall heat loss coefficient and domestic energy gain factor for single-family buildings. Building and Environment, Vol 37, Issue 11, 2001, p. 1019-1026.

16. Ziembicki, P. Analysis of topography of district heating network control chambers placement (Analiza rozkładu topograficznego komór telemetrycznych czynnej sieci ciepłowniczej), PhD dissertation, Wroclaw, Poland. PWr, 2004. 183 p. (in Polish).

\section{CENTRALIZUOTŲ ŠILUMOS TINKLŲ ANALIZĖS MONITORINGAS PAGAL NEURONINIŲ TINKLŲ KLASIFIKACIJĄ}

\section{P. Malinowski, P. Ziembicki}

\section{Santrauka}

Darbe siūlomas alternatyvus būdas centralizuoto šilumos tiekimo monitoringo parametru parinkimo problemai spręsti. Šis būdas paremtas tam tikromis sąlygomis, pavyzdžiui, faktinio realaus centralizuoto šilumos tinklo duomenimis ir specialistų žiniomis. Straipsnis sudarytas iš keturių dalių. Ivadinis žodis ir monitoringo parametrų parinkimo problema pateikiama pirmojoje dalyje. Teoriniai neuroninių tinklų pagrindai pristatomi antrojoje dalyje. Trečiojoje dalyje aprašoma neuroninių tinklų struktūra ir aptariami modeliavimo rezultatai. Ketvirtojoje dalyje pateikiamos išvados.

Raktažodžiai: centralizuoto šilumos tiekimo tinklai, monitoringas, neuroniniai tinklai, neuroninè klasifikacija.

Pawel MALINOWSKI. Doctor. He has been working since 1991 at the Wrocław University of Technology, Poland. He is adjunct at the District Heating and Ventilation Chamber. He teaches energy, energy systems, natural gas and domestic water systems and instalations, as well as modelling, mathemathical modelling, data analysis, control systems. He conducted research in different domains such as optimisation of energy systems, analysis of monitoring data, neural networks and fuzzy logic models of air-pollutants movement. He has published about 70 papers. His research interest is focused on applying the computer science methods to modelling of energy systems.

Piotr ZIEMBICKI. Doctor. He is working at the Environment Protection Institute of University of Zielona Góra, Poland. He got his $\mathrm{PhD}$ in 2004 after completing a research study on applying neural networks to optimise the number of control chambers of district heating network. Since that time his research interest is still focused on neural networks and control systems used in energy systems like district heating networks, building heating instalations and heating plants. 